Article

\title{
Five-Year Climatology of Local Convections in the Dabie Mountains
}

\author{
Linlin Zheng ${ }^{1,2,3}$, Jianhua Sun ${ }^{4,5, * \mathbb{C}}$, Xuexing Qiu ${ }^{1}$ and Zuxiang Yang ${ }^{1}$ \\ 1 Anhui Meteorological Observatory, Hefei 230031, China; zhengll.2@163.com (L.Z.); \\ qiuxuexing@126.com (X.Q.); yangzuxiang1@sina.com (Z.Y.) \\ 2 Anhui Institute of Meteorological Sciences, Hefei 230031, China \\ 3 Anhui Province Key Laboratory of Atmospheric Science and Satellite Remote Sensing, Hefei 230031, China \\ 4 Key Laboratory of Cloud-Precipitation Physics and Severe Storms (LACS), Institute of Atmospheric Physics, \\ Chinese Academy of Sciences (IAP/CAS), Beijing 100029, China \\ 5 Southern Marine Science and Engineering Guangdong Laboratory (Zhuhai), Zhuhai 510275, China \\ * Correspondence: sjh@mail.iap.ac.cn
}

Received: 23 October 2020; Accepted: 16 November 2020; Published: 18 November 2020

\begin{abstract}
Local Convection in Dabie Mountains (LCDM) occurs more frequently over the Dabie Mountains and brings severe weather to adjacent areas. In order to understand the characteristics of LCDM, their spatial distribution, the monthly and diurnal variations, and possible mechanisms are investigated. Based on radar composite reflectivity data over the 5-y period of 2014-2018 during warm seasons (April-September), a total of 195 cases of LCDM are identified. The LCDM exhibits maximum frequency on the windward slopes of the Dabie Mountains with a secondary maximum on lee slopes. It is demonstrated that LCDM peaks in July and August, while their diurnal variation exhibits a major peak in the afternoon during 12:00-16:00 local solar time (LST). Most LCDM does not leave the Dabie Mountains (NoOut-Type), accounting for $89.7 \%$ overall, and has an average $3.5 \mathrm{~h}$ lifespan. In contrast, the lifespans of Out-Types (i.e., LCDMs that move away from the Dabie Mountains) are longer ( $5.8 \mathrm{~h}$ on average), while most Out-Type LCDMs develop on southern slopes ('South-Type') and a few are also reinforced on northern slopes ('North-Type'). The South-Type mainly produces short-duration heavy precipitation, while the 'North-Type' predominately generates thunderstorms high winds. It is suggested that LCDM is thermally induced, and that both the 'South-Type' and 'North-Type' are controlled by southerly wind perturbation. Lifting by upslope wind and heat sources over windward slopes has led to 'South-Type' development, while ascent induced by wave-like perturbations on lee slopes has led to 'North-Type'. These mechanisms should be further investigated in future work by using field experiments and numerical simulations.
\end{abstract}

Keywords: Dabie Mountains; local convections; upslope winds; heat sources

\section{Introduction}

A range of studies both in China and around the world have revealed that convections occur frequently in mountainous areas. Research has shown that there are a number of favorable locations globally for the initiation of convection over mountains (e.g., in the mountains of Colorado and New Mexico [1]). Convection initiation (CI) reported for the Vosges and Black Forest mountains by Aoshima et al. [2] showed that CI density was about three times higher in mountainous regions than in valleys. Indeed, tornadoes and funnel clouds are frequently observed in the Rocky Mountains in late spring and summer [3]. Downbursts and micro-downbursts tend to occur adjacent to mountainous areas [4], while severe hail storms also mostly occur near these regions, including on the plateau around lee slopes of the Rockies [5], the eastern part of the Canadian Alberta Rockies ([6,7]), the northern part of 
the Jura Mountains in central Switzerland, and the southern region of the Alps [8]. It is demonstrated that the convection frequency occurred in mountainous areas is higher than in plain areas across China at the same latitude $[9,10]$.

The Dabie Mountains are located at the junction between Anhui, Hubei and Henan provinces in China. The main component of these mountains is about $1500 \mathrm{~m}$ above sea level (ASL), the watershed between the Yangtze and Huaihe rivers. Annual average precipitation over these mountains is $1832.8 \mathrm{~mm}, 360 \mathrm{~mm}$ more than seen in nearby areas [11]. Precipitation as well as severe convective weather events occur more frequently over the Dabie Mountains than they do in adjacent areas. Lightning data collected across Anhui Province, China, during 1971-2000 also reveal that this kind of activity over the Dabie Mountains is significantly enhanced compared to nearby areas at the same latitude [12]. Precipitation and convection in nearby areas can also be affected by terrain; in spring and summer, mesoscale convective systems (MCSs) often develop in the northern Dabie Mountains, leading to heavy rainfall and other severe convective weather events [13]. Zhao et al. [14] revealed that precipitation is enhanced in the northwest of Anhui Province as a result of airflow climbing within this range. Indeed, during the Meiyu period, rainstorms moved into lee wave positions of the Dabie Mountains and enhanced precipitation [15]. It is clear that the topography of the Wannan mountainous region as well as the Dabie Mountains have an impact on the intensity and distribution of rainstorms. Mesoscale topographic features formed by these landmasses strengthen heavy rainfall across the southern Anhui Province [16]. Dabie Mountains' topography also exerts a significant impact on tropical cyclone precipitation enhancement and can also alter the position of heavy rainfall [17].

The impacts of mountainous topography on atmospheric circulation, storm paths, and water vapor transport are complex. Similarly, the impacts of topography on the occurrence and development of MCSs are also complex. It has been recognized that topography exerts a marked impact on CI through dynamic forcing (e.g., lee-side convergence, wake effects, flow into convergent valleys, and orographic lifting) and thermal forcing [1]. In one earlier study, Kovacs and Kirshbaum [18] revealed that CI maxima tend to occur within river valleys as well as in the prominent mountain ridges lee, where moisture and mass converged based on 22-y radar climatology and quasi-idealized simulations. Severe convective weather and tornadoes are produced by a mixed layer uplift in mountainous areas [19], while the impacts of gravity waves on the lee slope $[15,20,21]$ and storm outflows colliding with mountain upward winds [22-24] have also been studied.

Research on convective activities in other mountainous areas has also been conducted. A radar climatology of summertime convective clouds in the Black Hills was carried out by Kuo and Orville [25]. Lin et al. [26] investigated the climatology of thunderstorms in Taiwan, which is a mountainous island. Although numerous studies have been carried out on convection and precipitation due to the topographic impacts of the Dabie Mountains, statistical studies on Local Convection in Dabie Mountains (LCDM) still need to be performed, like many other studies on general features of MCSs [27], preceding landfalling tropical cyclones (pre_TC) squall lines [28], and squall lines in the East China [29]. The goal of the study is therefore to investigate the spatial distribution of LCDM as well as their temporal variations, lifespans, and their possible relevance to various severe convective weather events. The data and methodologies used in this study are presented in Section 2, while general LCDM features are discussed in Section 3. Two distinct Types of LCDM, as well as their possible mechanisms, are compared in Section 4, while discussions and conclusions are presented in Section 5.

\section{Data and Methodology}

\subsection{Study Region and Database}

The aim of this study is to investigate the general features of local convections initiated over the Dabie Mountains (30.17-32.52 $\left.\mathrm{N}, 114.70-117.17^{\circ} \mathrm{E}\right)$. These mountains extend about $380 \mathrm{~km}$ from east-to-west and are $175 \mathrm{~km}$ wide from south to north. These mountains are located between the Yangtze and Huaihe rivers at the border between the Henan, Hubei, and Anhui provinces and have 
average heights between $500 \mathrm{~m}$ and $800 \mathrm{~m}$ (Figure 1). The highest peak of the Dabie Mountains is called Tiantangzhai; this peak is $1729 \mathrm{~m}$ ASL (Figure 1) and forms the watershed between the Yangtze and Huaihe rivers. The study area for this research is highlighted by the polygon in Figure 1 and is more than $200 \mathrm{~m}$ ASL. The five points of the polygon in Figure 1 are $\left(30^{\circ} \mathrm{N}, 116^{\circ} \mathrm{E}\right),\left(31.3^{\circ} \mathrm{N}, 117.2^{\circ} \mathrm{E}\right)$, $\left(32.1^{\circ} \mathrm{N}, 115.9^{\circ} \mathrm{E}\right),\left(31.6^{\circ} \mathrm{N}, 115.6^{\circ} \mathrm{E}\right)$ and $\left(31^{\circ} \mathrm{N}, 115^{\circ} \mathrm{E}\right)$, respectively.

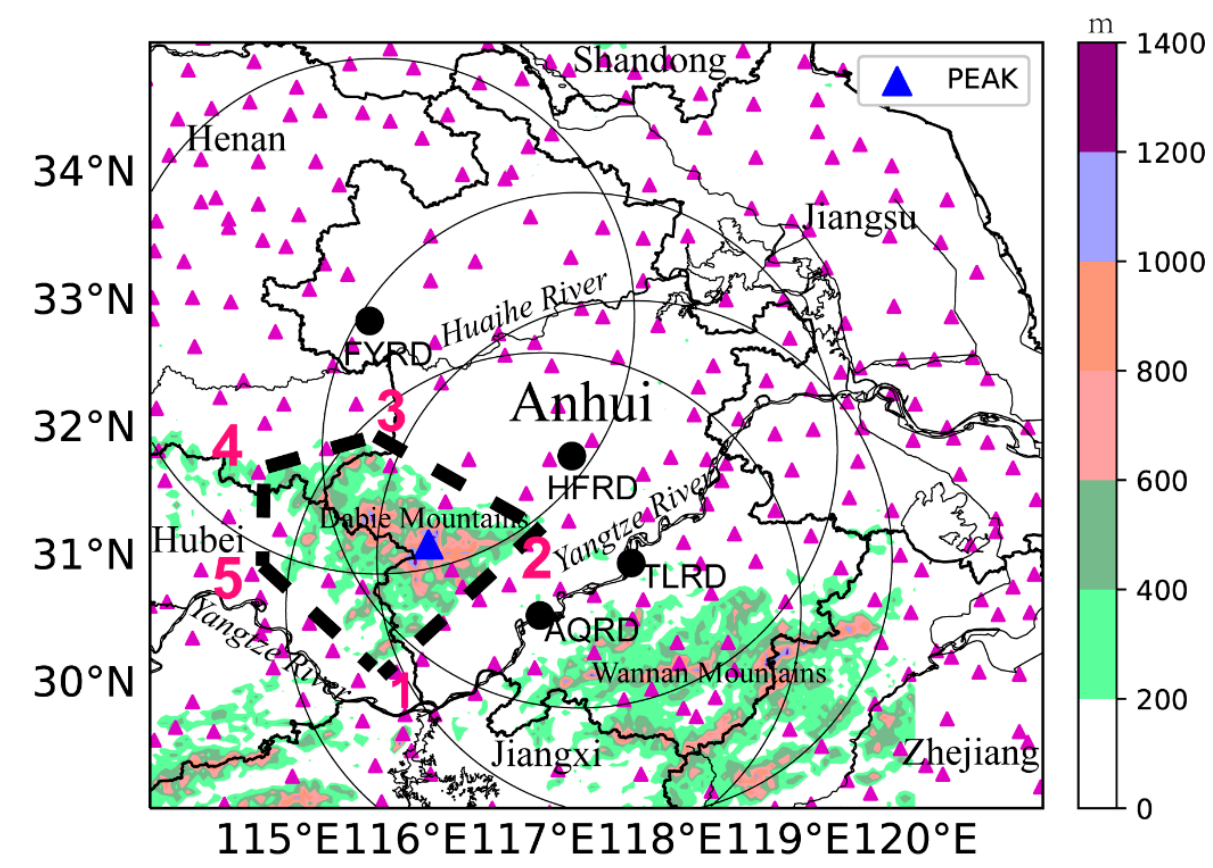

Figure 1. The elevations (shaded, unit: $\mathrm{m}$ ) and observational stations of severe weather (thunderstorm high winds (THWs) and hails, purple triangle) over Yangtze Huaihe River region. The black dots represent radar stations ('HFRD' represents Hefei radar, 'FYRD' represents Fuyang radar, 'AQRD' represents Anqing radar, and 'TLRD' represents Tongling radar). The solid circle represents the detection range of corresponding radar. The bold dashed polygon represents Dabie mountain areas. The blue triangle represents the highest peak of Dabie Mountains.

By using 5 years of composite reflectivity data from four radar stations (i.e., Hefei, Fuyang, Anqing, and Tongling) (Figure 1) at a time resolution of $6 \mathrm{~min}$ and spatial resolution of $0.01^{\circ} \times 0.01^{\circ}$, the $\mathrm{LCDM}$ cases were identified during 2014-2018 in warm seasons (April-September). Composite reflectivity data were retrieved from the Severe Weather Automatic Nowcasting System (SWAN) [30] which is developed by the China Meteorological Administration. The quality control techniques used in SWAN for composite reflectivity data include filtering isolated noises, ground clutter and super-refraction echoes $[30,31]$.

Severe convective weather produced by LCDM are analyzed using hourly precipitation observational data collected from a total of 2308 automatic stations across the study area (not illustrated here due to their high density) alongside special weather observational data (Figure 1). Applying the Severe Weather Prediction Center operational rules outlined by the China Meteorological Administration, LCDM-related severe convective events including short-duration heavy precipitation (SDHR, hourly rainfall $\geq 20 \mathrm{~mm} / \mathrm{h}$ ), thunderstorm high winds (THWs) $\geq 17 \mathrm{~m} / \mathrm{s}$, and hail $\geq 4 \mathrm{~mm}$ in diameter are also investigated.

The ECMWF_ERA5 (ERA5) hourly re-analysis (resolution $0.25^{\circ} \times 0.25^{\circ}$ ) are used to investigate corresponding synoptic weather conditions. In this approach, ERA5 is able to combine vast amounts of historical observations into global estimates using advanced modelling and data assimilation systems. ERA5 provides hourly estimates for a large range of atmospheric, land, and oceanic climate variables. 


\subsection{LCDM Identification and Tracking}

A local convection identification algorithm was used to determine the initial locations and timings of LCDM. A convection tracking algorithm was then used to track the route of each case and to create convection paths and an end-time dataset. The characteristics of LCDM initial locations, movement paths, and lifespans were then investigated.

\subsubsection{LCDM Identification}

LCDM identification included two steps. Firstly, radar reflectivity was used to identify convections in the Dabie Mountains. Secondly, a tracking-back algorithm and artificial recognition technique were combined to select convections that initiate in the Dabie Mountains and exclude storms that move into the area.

Reflectivity Thresholds for Identify Convections in the Dabie Mountains

An area of composite reflectivity $\geq 40 \mathrm{dBZ}$ at least $16 \mathrm{~km}^{2}$ areal coverage was implemented as part of the local convection identification algorithm. A threshold of $40 \mathrm{dBZ}$ is considered a reasonable criterion for convective activity here, as this has been applied in other research [32-34]. Based on the threshold, a graphic recognition algorithm was used to recognize continuous echo within Dabie Mountains (Figure 2a).
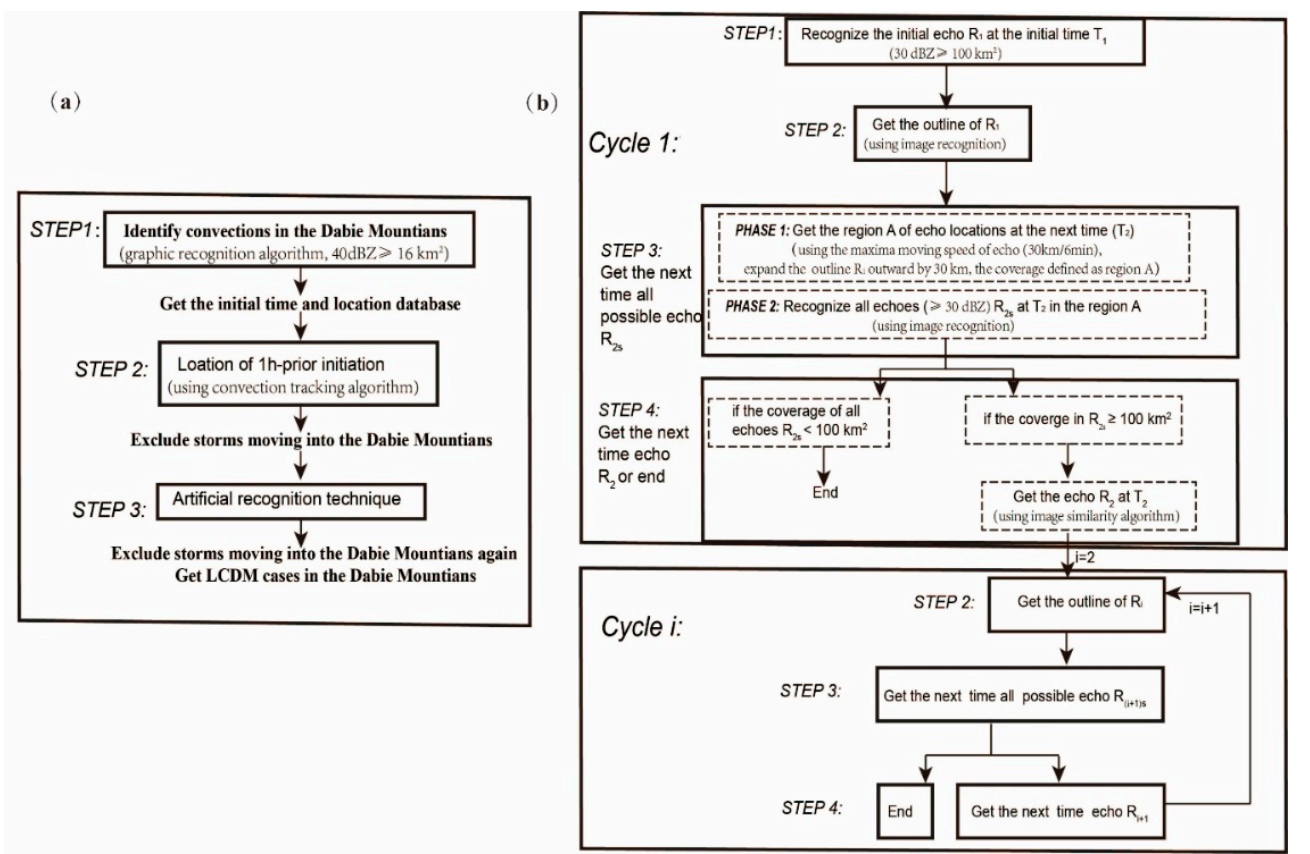

Figure 2. The flow chart of (a) the local convection identification algorithm and (b) the tracking process of LCDM.

Selecting Convections that Initiate in the Dabie Mountains

We are only selecting storms that initiate in the Dabie Mountain region and do not want to consider systems that move into the area, and this can be called the identifying LCDM process. A tracking-back algorithm and artificial recognition technique were combined to identify LCDM in this process. The tracking-back algorithm used here is the convection tracking technique described in Section 2.2.2. Target echoes were tracked back 1-h prior to their initial time; thus, if a $1 \mathrm{~h}$-back location falls within the Dabie Mountains, it was classified as a local convection (Figure 2a). After the tracking-back algorithm, artificial recognition is applied. Manually identifying each case 1-h back from the initial time allowed us to exclude incoming cases again (Figure 2a). 
Base on the two steps mentioned in Section 2.2.1, LCDM databases including initial times and locations were obtained. Then, the convection tracking process is applied to obtain the storm tracks based on the LCDM databases.

\subsubsection{LCDM Tracking}

Two different thresholds are used in the identification and tracking technique. After identifying LCDM using the threshold of $40 \mathrm{dBZ}$, a lower threshold of $30 \mathrm{dBZ}$ is used in convection tracking technology for all the LCDM. As the shape and outline of echoes $\geq 40 \mathrm{dBZ}$ change frequently because they often merge or split, this criterion is problematic to implement in convection tracking technology using image similarity. The statistical results of all LCDM in this study demonstrated that convections recognized at a $40 \mathrm{dBZ}$ threshold of at least $16 \mathrm{~km}^{2}$ exhibit $30 \mathrm{dBZ}$ coverage of at least $100^{2} \mathrm{~km}$; therefore it is not contradictory to use a higher value $(40 \mathrm{dBZ})$ in the identification and a lower value ( $30 \mathrm{dBZ})$ in the tracking process.

An image similarity algorithm [35] was applied in convection tracking technology, comprising four steps (Figure 2). The first step in this process involved determining initial echo $\mathrm{R}_{1}$ using the local convection identification algorithm already discussed in Section 2.2.1, but applying a threshold of $30 \mathrm{dBZ}$ at least $100 \mathrm{~km}^{2}$. The second step then involved determining the $\mathrm{R}_{1}$ outline via image recognition [36,37] after binarization and median filtering [38]. The third step then determined all possible echoes of $R_{2 s}$ at the next time $T_{2}$, whichincludes two phases (Figure $2 b$ ). Specifically, in Phase 1 , the region $A$ of echo location at $T_{2}$ was determined by expanding the $R_{1}$ outline outward by the distance of $30 \mathrm{~km}$. This distance represents the maximum distance of storms moving over 6-min (about $300 \mathrm{~km} / \mathrm{h}$ ). Therefore, region A represents the areas where R1 is moving to at the next time. In Phase 2, all echoes of $R_{2 s} \geq 30 \mathrm{dBZ}$ at $T_{2}$ were identified in region $A$. The fourth step determined if, during the next time, echo $R_{2}$ existed or not. If all the echoes of $R_{2 \mathrm{~s}}$ were smaller than $100 \mathrm{~km}^{2}$, then the tracking processes was ended, and if not, the echo $R_{2}$ was the one of $R_{2 s} \geq 100 \mathrm{~km}$, the most similar to $R_{1}$ within region A using an image similarity algorithm. In this approach, $R_{2}$ is regarded as the echo which $R_{1}$ moves between $T_{1}$ and $T_{2}$. The cycle (between step 2 to step 4, "Cycle $i$ " in Figure $2 b$ ) was then repeated to obtain $R_{3,4,5 \ldots n}$ at time $T_{3,4,5} \ldots \mathrm{n}$ until coverage of all echoes $R_{3 s, 4 s, 5 \mathrm{~s} \ldots \text { ns }}$ were less than $100 \mathrm{~km}^{2}$. The tracking processing used here is shown in Figure $2 \mathrm{~b}$.

We do not include a minimum threshold for the life cycle of the system, for two reasons. First, the Dabie Mountains is a relatively small area. In order to obtain a large sample size of local convection, we do not include a minimum threshold. Second, because most LCDMs in the Dabie Mountains are isolated, but not organized, their size is relatively small and most of them are short-lived.

\section{Spatial Distribution and Temporal Variations}

On the basis of the method described in Section 2, a total of 195 cases were obtained for the five-year (2014-2018) warm seasons, with 39 annual occurrences on average (Table 1). It is demonstrated that LCDM increased annually over the period between 2014 and 2018; the number seen in 2018 was twice that seen in 2014. The increasing trend of LCDM possibly resulted from global warming. As

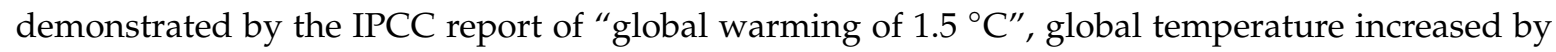
$0.2 \pm 0.1^{\circ} \mathrm{C}$ per decade [39]. In addition, Qi et al. [40] claimed that the duration of the high-temperature heat wave in eastern China tends to be prolonged. LCDMs that do not leave the Dabie Mountains are defined as NoOut-Type, while LCDMs that move away from the Dabie Mountains are considered as Out-Type. 
Table 1. The number of local convections in Dabie Mountains during 2014-2018 in the warm seasons (from April to September).

\begin{tabular}{cccccccc}
\hline Year & $\mathbf{2 0 1 4}$ & $\mathbf{2 0 1 5}$ & $\mathbf{2 0 1 6}$ & $\mathbf{2 0 1 7}$ & $\mathbf{2 0 1 8}$ & Total & Annual Mean \\
\hline LCDM & 22 & 36 & 38 & 49 & 50 & 195 & 39 \\
Out-Type & 3 & 4 & 3 & 4 & 6 & 20 & 4 \\
NoOut-Type & 19 & 32 & 35 & 45 & 44 & 175 & 36 \\
\hline
\end{tabular}

\subsection{Spatial Distribution}

The initial locations of the 195 cases reported here are summarized in Figure 3a. Three high-elevation areas (i.e., higher than $1000 \mathrm{~m}$ ) denoted A, B, and C (rectangles) within the Dabie Mountains, which are illustrated in Figure 3. Initial locations are concentrated within areas to the south of A and B, respectively, as well as to the north of C (denoted as AR, BR, and CR in Figure 3a). The elevations of these three areas fall between 400 and $800 \mathrm{~m}$. The results indicate that most LCDMs do not initiate on the highest mountains, but over slopes; AR and BR are located on the southern slopes of the Dabie Mountains (will be indicated as the windward slopes in Section 4.1), while CR falls on the northern slopes (will be indicated as the lee slopes in Section 4.1). Maximum storm activity along the windward slopes rather than at higher elevations was also investigated in Taiwan [41-43]. A small number of LCDM cases were generated over mountain tops within the Dabie Mountains, as CI is complex in different mountainous areas. A number of previous studies have revealed that favorable CI tends to occur on mountain tops [44-46] not just because of elevation but also because of steeper slope angles [46]. In earlier work, Banta and Schaaf [1] indicated that the lee-side of mountain areas often tends to be conducive for convection generation, while Yang et al. [47] demonstrated that most MCSs are initiated on the eastern edges of second-step terrain.

Average composite reflectivity at the time of initiation for all 195 convections, as summarized in Figure $3 b$. High reflectivity falls to the south of areas A and B (Figure 3b), consistent with AR and BR's initial locations (Figure 3a). At the same time, one additional area is also present at the higher elevation $\mathrm{C}$ as well as to the east of area B, inconsistent with CR initial locations (Figure 3a). Higher reflectivity (i.e., composite reflectivity greater than, or equal to, $40 \mathrm{dBZ}$ ) also occurs frequently across these three areas (Figure 3c), consistent with the results in Figure 3b. These results indicate that most LCDMs, including severe ones, tend to initiate on windward slopes. Numerous previous studies have revealed the enhancement effects of windward slopes on precipitation within the Dabie Mountains [17,48]. In one example, $\mathrm{Ni}$ et al. [49] revealed that maximum annual precipitation occurred to the southeast of the Dabie Mountains peaks, consistent with the high reflectivity in the southeast of area B (Figure 3b,c). A limited number of studies have emphasized the impact of windward slope convection, especially within the Dabie Mountains. 

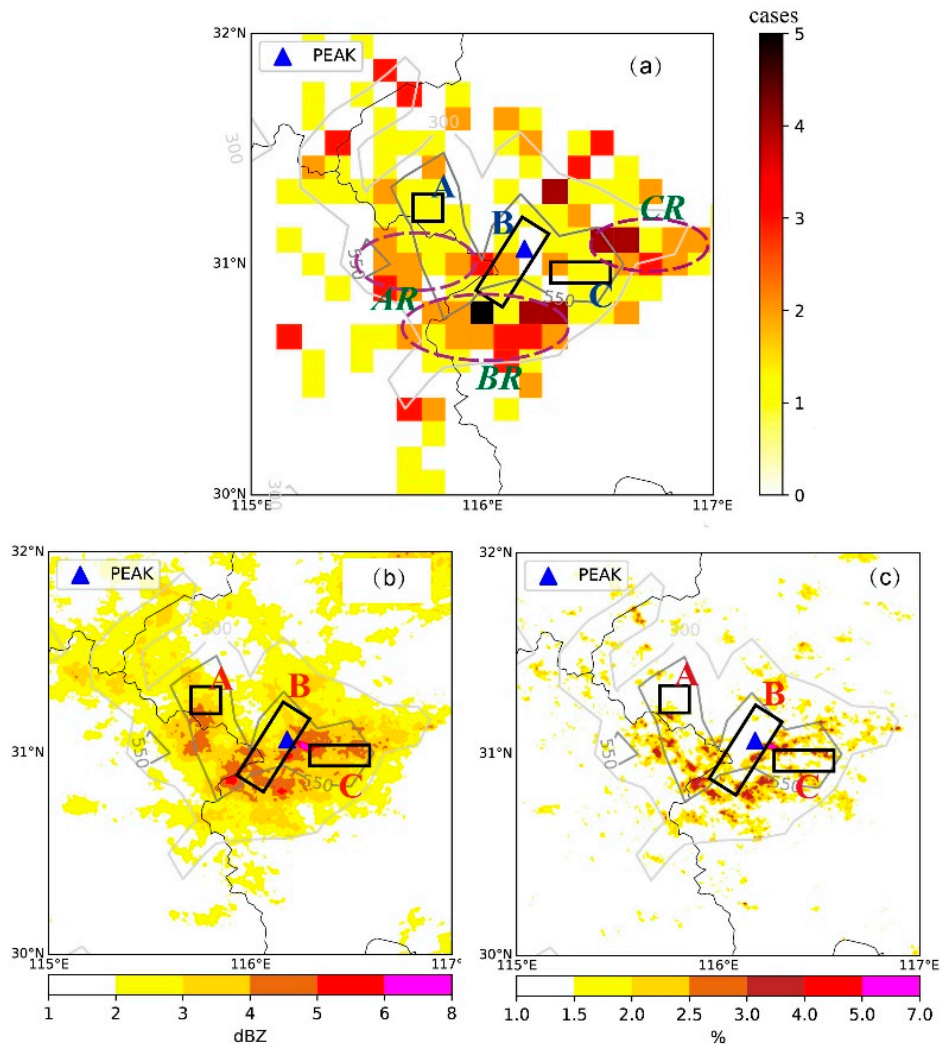

Figure 3. (a) The elevations (contour, unit: $\mathrm{m}$ ) and the numbers in $10 \times 10 \mathrm{~km}$ of LCDM; (b) The elevations (contour, unit: $\mathrm{m}$ ) and the spatial distribution of composite reflectivity average (shaded, unit: dBZ) and (c) the probability distribution of composite reflectivity $\geq 40 \mathrm{dBZ}$ (shaded, unit: \%) of LCDM during the warm seasons (from April to September) of 2014-2018. The black rectangles represent high altitude of Dabie mountains. The dashed ellipses represent the areas of high frequency of LCDM genesis.

\subsection{Monthly and Diurnal Variations}

LCDM tend to increase from April to August, occur frequently in summer (June-August) and peak in August (Figure 4a). The monthly variations in LCDM are different from those of long-lived organized MCSs on plain areas (e.g., in the central United States), which peak in May, June, and July [50]. The monthly variations in LCDM and long-lived organized MCSs in east China are different. For example, long-lived MCSs in other mountainous regions (e.g., over second-step terrains in the Yangtze River Valley and over central-east China) exhibit different monthly variations, with peaks in June and July [27], perhaps related to the Meiyu Front. It is generally the case that this major rain band is controlled by the summer monsoon over the middle and lower reaches of the Yangtze River in eastern China and this peaks during middle June to middle July [51]. Climatological studies over this area suggest that convection and associated precipitation are affected by terrain [52,53]. Convection on mountainous areas in France and Germany also occurred frequently in summer [54]. 

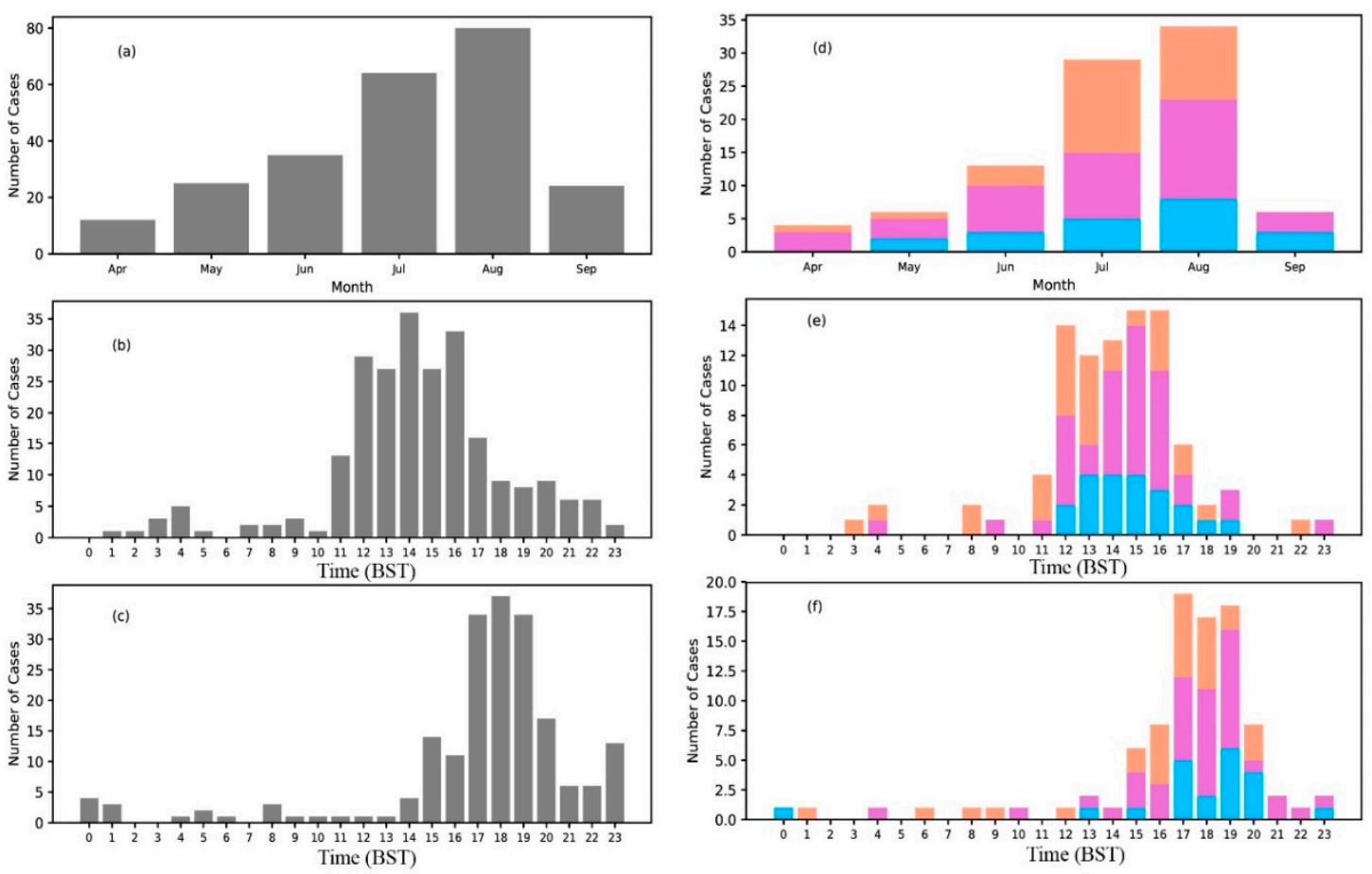

Figure 4. (a,d) Monthly variations, (b,e) initial time and (c,f) dissipating time of LCDM (grey column), LCDM in AR areas (blue column), LCDM in BR areas (purple column) and LCDM in CR areas (orange column) in Figure 3a in Dabie Mountains during the warm seasons (from April to September) of 2014-18.

In terms of diurnal variations, LCDM appears a single peak at 12:00 Beijing Standard Time (BST) - 16:00 BST (Figure 4b), dominated by afternoon convection, possibly due to maximum solar heating [25]. This afternoon peak also indicates its heating-induced characteristics. The diurnal variations in LCDM are also different here from those seen in other areas of Central East China; in one example, MCSs in Eastern China appear to have two peaks, a main one in the afternoon and a second one in the early morning [9]. Meng et al. [29] revealed that the squall line initiated over the north of $30^{\circ} \mathrm{N}$ in East China peaks at noon (09:00-12:00 BST), while preceding landfalling tropical cyclones (pre-TC) squall lines form a peak extending from the afternoon to midnight [28].

It can be noted that LCDM exhibits heating-induced properties with monthly and diurnal variations. Indeed, most LCDMs dissipate between the afternoon and midnight (between 15:00 and 23:00 BST), $88.2 \%$ of the total. Overall, 53.8\% of this total dissipated at 17:00-19:00 BST (Figure 4c). The lifespans of LCDM are generally shorter than six hours.

There are slight differences among AR, BR, and CR areas. LCDM in AR and BR areas peak in August, while those in CR areas peak in July (Figure 4d). Similarly, LCDM in AR and BR areas peak at 12:00-16:00 BST, while those in CR areas peak at 11:00 and 16:00 BST (Figure 4e). The majority of LCDMs in AR, BR, and CR areas dissipate at 17:00-20:00 BST, 15:00-19:00 BST, and 15:00-18:00 BST, respectively (Figure 4f). LCDMs in AR and BR areas tend to exhibit similar monthly and diurnal variations, while those in $C R$ areas appear and dissipate an hour earlier than in corresponding $A R$ and $\mathrm{BR}$ areas. The results indicate that the lifespans of LCDM in these three areas are similar.

The evolutionary distribution of reflectivity $\geq 40 \mathrm{dBZ}$ frequencies during the period 12:00-17:00 BST are shown in Figure 5. Indeed, similar to the orange column in Figure 4b, LCMD in CR areas (Figure 3a) initiate at 12:00 BST on northern slopes (Figure 4e). The maximum frequency on the southern slopes of AR and BR (Figure 3a) occurred between 13:00 and 15:00 BST (Figure 4e), an hour later than in CR areas. In general, LCDMs frequently initiate on southern slopes with a secondary maximum on northern slopes. LCDMs generally move in a northeast direction, but most dissipate within the Dabie Mountains (Figure 5). 

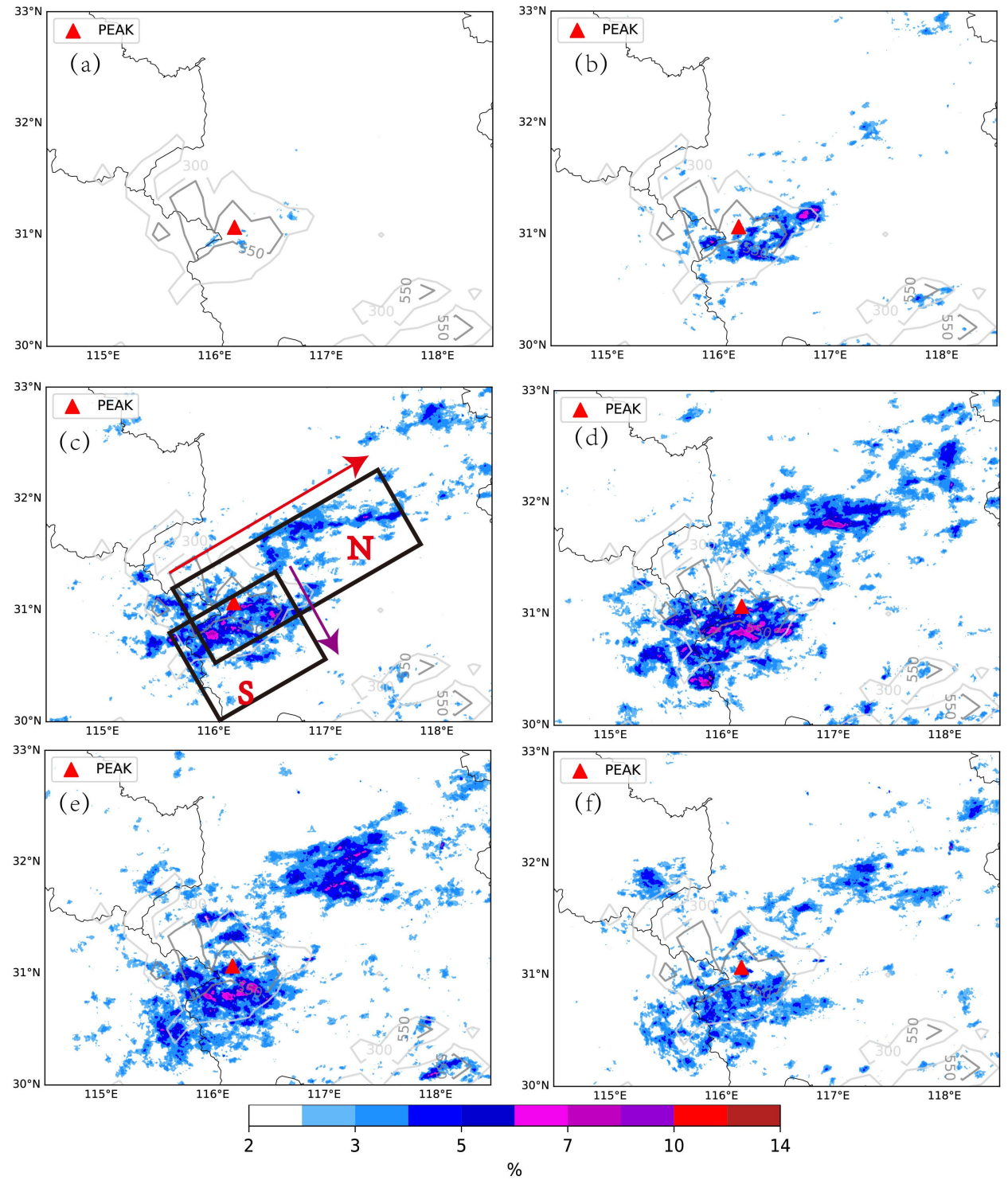

Figure 5. Frequencies of occurrence (\%) for reflectivity $>40 \mathrm{dBZ}$ at (a) 12:00, (b) 13:00, (c) 14:00, (d) 15:00, (e) 16:00, and (f) 17:00 BST. The two rectangle boxes in (c) indicate the subdomains for calculating the Hovmöller diagrams in Figure 6. The red arrow represents the x-axis direction of Figure 6a, and the purple arrow represents the $x$-axis direction of Figure $6 \mathrm{~b}$.

The Hovemöller diagram [32,55,56] (Figure 6) is used to demonstrate the diurnal variations and motion characteristics of LCMD in the $\mathrm{N}$ and $\mathrm{S}$ subdomains (Figure $5 \mathrm{c}$ ). It is demonstrated in Figure 5 that LCMD initiated an hour earlier over northern slopes than that over southern slopes, the former moved to northeast plain areas, and the latter affected the southeast valley areas. The $\mathrm{N}$ and $\mathrm{S}$ subdomain cover the LCDM initiation and affecting areas. In addition, LCDM over northern slopes moves along the long side of $\mathrm{N}$ subdomain (in the direction of the red arrow in Figure $5 \mathrm{c}$ ), and that over southern slopes propagates along the short side of $\mathrm{S}$ subdmain (in the direction of the purple arrow in Figure 5c). In order to demonstrate the diurnal variations and propagation of LCDM initiated over northern slopes, the Hovemöller diagram along the long side of $\mathrm{N}$ subdomain from west to east (the red arrow direction in Figure 5c) was presented, and the short side of the $\mathrm{N}$ subdomain is averaged. For LCDM initiated over southern slopes, the Hovemöller diagram along the short side of $S$ subdomain from north to south (the purple arrow in Figure 5c) was presented, and the long side of $S$ subdomain is averaged. Most LCDMs initiate on southern slopes and have a maximum frequency at 
15:00 BST (Figure 6b), similar to the results presented in Figure 4e (purple column). However, most of them do not move away from southern slopes and the rest move southeast, along the short side of subdomain $\mathrm{S}$ (Figure 5c), at most, 30km distance away from southern slopes to foothills (Figure 6b). The diurnal propagation of LCDM over northern slopes is different, which initiates at 13:00 BST, and moves northeast, along the long side of subdomain N (Figure $5 \mathrm{c}$ ), away from mountainous areas. These then develop again at foothills and plains.
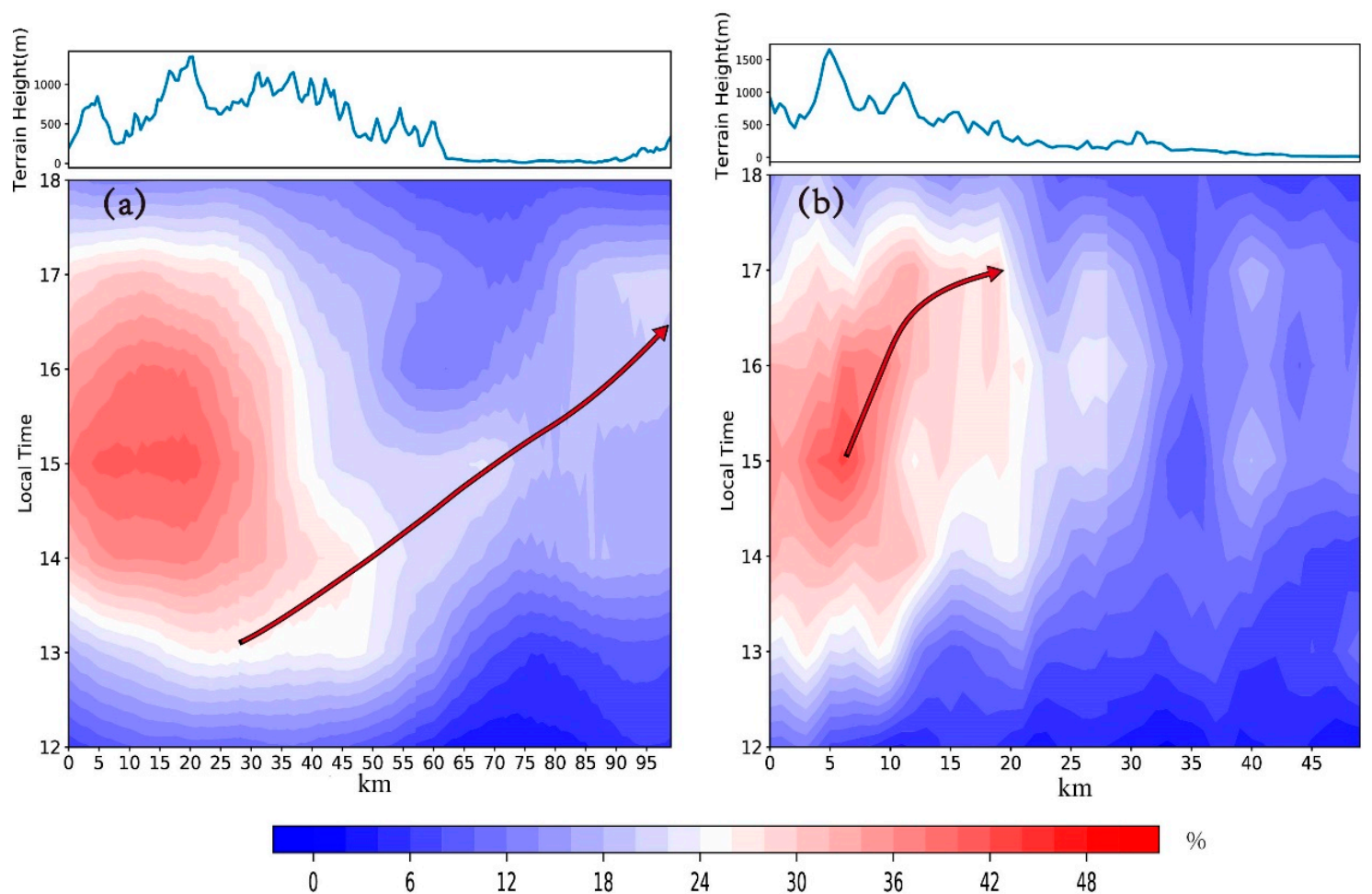

Figure 6. Hovmöller diagrams of the frequency of occurrence (\%) of reflectivity $\geq 40 \mathrm{dBZ}$ for subdomains (a) $\mathrm{N}$ box and (b) $\mathrm{S}$ box. The frequency is averaged along the short (long) side of subdomain $\mathrm{N}$ (S) box, as indicated in Figure 5c. The average topographic profile is also indicated at the top of each panel.

\subsection{Lifespans}

Based on the tracking algorithm of the 195 cases, 175 cases dissipated within the Dabie Mountains (NoOut-Type), and, accounting for $89.7 \%$ of the total, consistent with the results presented in Figures 5 and 6 . In contrast, 20 Out-Type cases account for just 10.3\% of the total (Table 1). The lifespans of most LCDMs are less than $6 \mathrm{~h}$, accounting for $86.67 \%$ of the total, with an average duration of $3.7 \mathrm{~h}$ (Figure 7a). Out-Type life spans are mostly $4-8 \mathrm{~h}$, accounting for $62.86 \%$ of the total, $5.8 \mathrm{~h}$ on average (Figure 7c). In contrast, the majority of NoOut-Type durations are up to $4 \mathrm{~h}$, accounting for $67.49 \%$ of the total, $3.5 \mathrm{~h}$ on average (Figure $7 \mathrm{~b}$ ). The duration of the Out-Type tends to be longer than those of the NoOut-Type. The lifespans of LCDM are comparable to those of MCSs [27] and squall lines (4 h on average [28]) across Eastern China. 

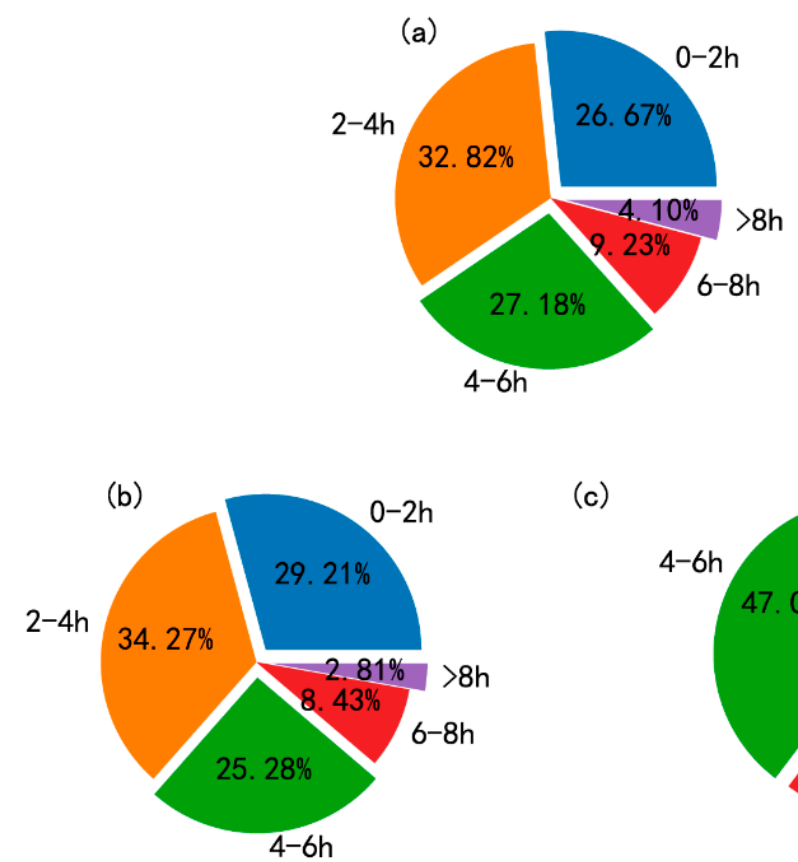

(c)

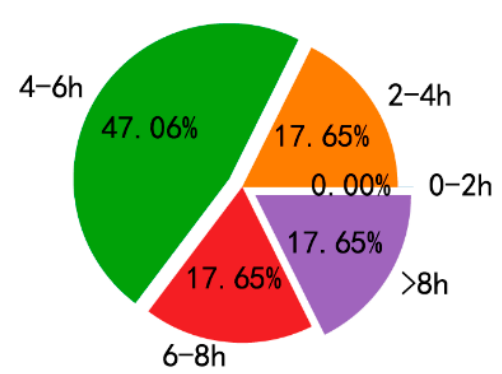

Figure 7. The lifespans (unit: hours) of (a) LCDM, (b) NoOut-Type and (c) Out-Type during the warm seasons (from April to September) of 2014-2018.

\subsection{Related Severe Convective Weather}

It is clear that LCDMs mainly produce SDHR, including all of the 195 cases studied in this analysis. Overall, just seven (3.5\%) led to THWs (six of which were Out-Type), while only one generated hail (figure not shown here). SDHR $\geq 50 \mathrm{~mm} / \mathrm{h}$ mostly occur within foothills at elevations around 200 $\mathrm{m}$ (Figure 8a), especially in the south and north of the Dabie Mountains. High-intensity (Figure 8a) and high-frequency (Figure $8 \mathrm{~b}$ ) SDHR are observed to the south and north of the Dabie Mountains, consistent with high values (Figure $3 b$ ) and frequencies (Figure 3c) of composite reflectivity. In recent work, Tong et al. [57] reported high SDHR frequencies over the south of the Dabie Mountains, and a similar trend was noted on Taiwan island by Lin et al. [26], where the maximum rain frequency occurred parallel to the orientation and lower slopes of the mountains.

THWs mainly occur in valleys to the south of the Dabie Mountains (Figure 8c). These events also tend to be less frequent in Dabie mountainous regions (Figure 8) and have lower frequencies than those over mountainous regions in North China, especially over the Taihang Mountains [58]; THWs also frequently occur over the eastern Rocky Mountains, and significant volumes ( $\geq 33.4 \mathrm{~m} / \mathrm{s}$ ) are seen over the Great Plains [59] in the United States. The results imply that topographic configuration is an important issue influencing THWs, which will require further analysis. 


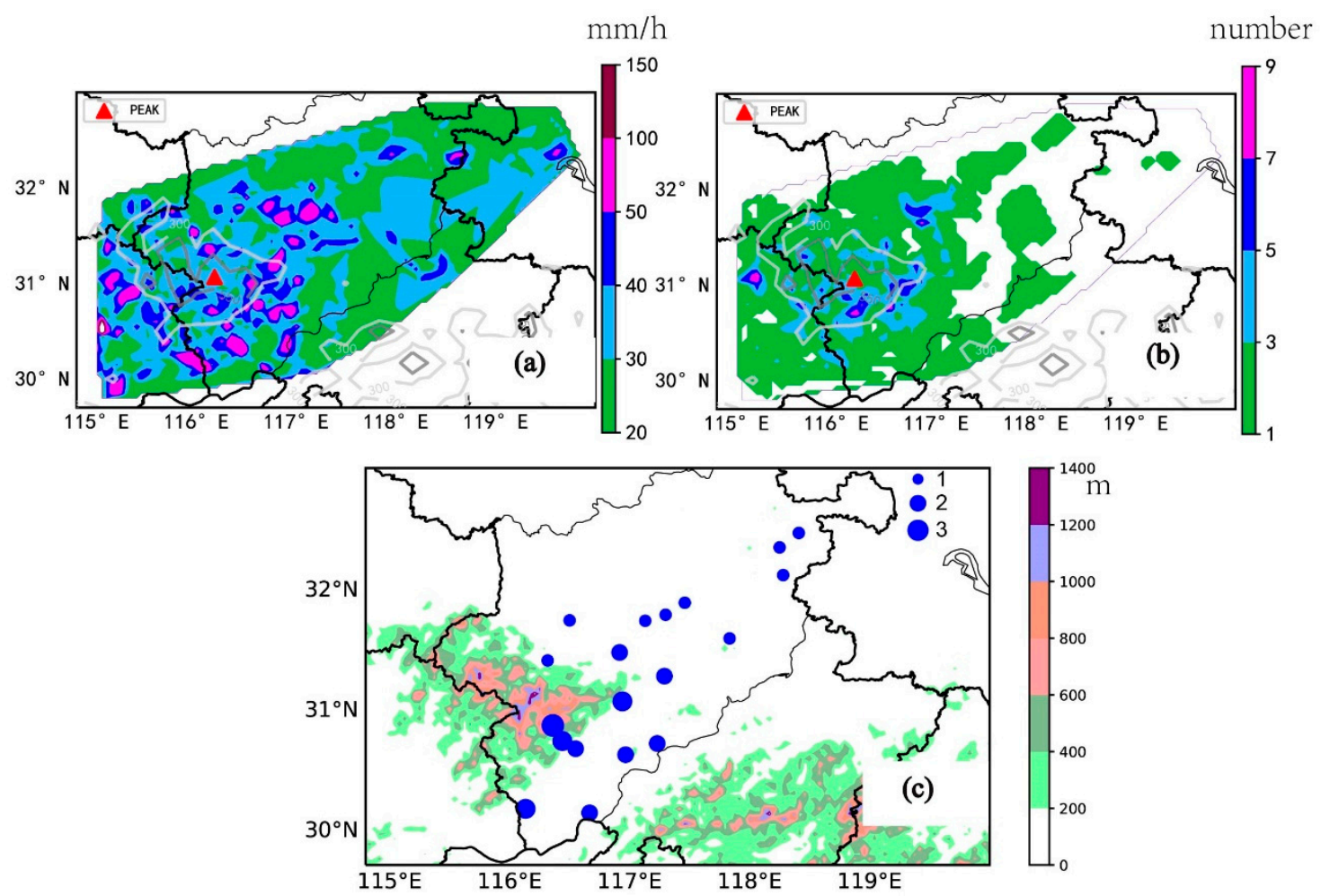

Figure 8. (a) The maximum hourly precipitation (shaded, unit: $\mathrm{mm} / \mathrm{h}$ ), (b) the frequencies of SDHR (shaded, unit: number), and (c) frequencies (unit: number) of THWs of LCDM during the warm seasons (from April to September) of 2014-2018. The contours represent elevations (unit: $\mathrm{m}$ ) in (a) and (b), and the shaded represent elevations (unit: $\mathrm{m}$ ) in (c).

\section{South- and North-Type Features}

\subsection{Developmental Characteristics}

The majority of Out-Type events (17 out of 20 cases) developed along moving paths away from the Dabie Mountains. Specifically, 12 cases developed over southern slopes ('South-Type'), while five developed over northern slopes ('North-Type'). The convection developed in southern slopes can also be observed in the Himalayas [60-63]. Indeed, the 'South-Type' developed to the southeast of the main peak (S area in Figure 9a), where maximum annual precipitation occurred [49]. 'North-Type' favorably developed at the junction between mountains and plains along the northern slopes of the Dabie Mountains (Figure 9b). 

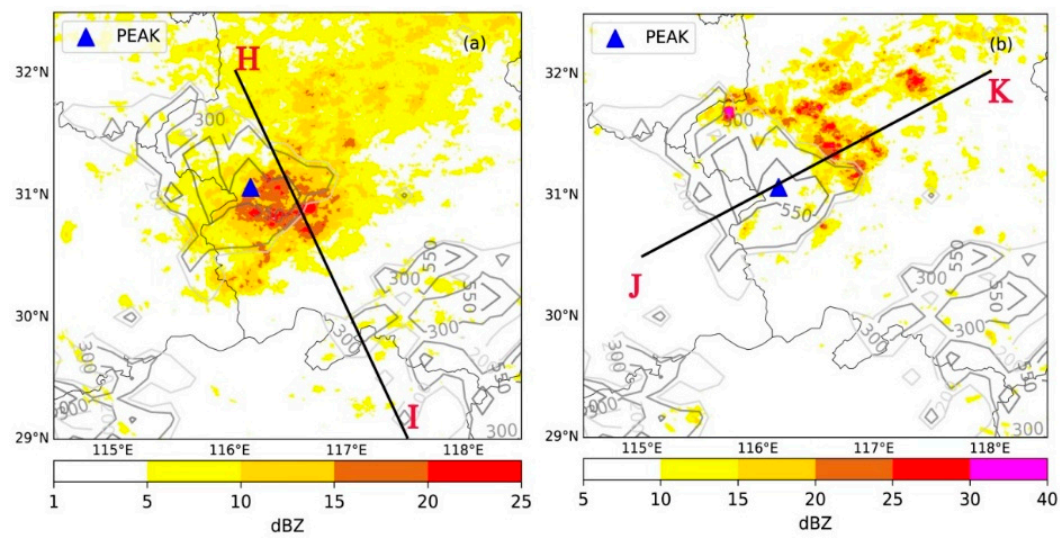

Figure 9. The spatial distribution of average composite reflectivity (shaded, unit: dBZ) of (a) 'South-Type' and (b) 'North-Type' of LCDM during the warm seasons (from April to September) of 2014-2018, in which the contours represent elevations (unit: $\mathrm{m}$ ). The black rectangles represent high altitude of Dabie mountains. The lines ' $\mathrm{HI}$ ' and ' $\mathrm{JK}^{\prime}$ represent the cross-section in Figure 11.

The average wind fields at 850 and $925 \mathrm{hPa}$ for 'South-Type', 'North-Type', and LCDM were analyzed using ECMWF_ERA5 hourly reanalysis data, respectively. The reanalysis data at the developed time for 'South-Type' and 'North-Type' as well as at the initial time for LCMD, were then averaged. As shown in Figure 10, both 'South-Type' and 'North-Type' develop in southwesterly winds; this means that the former develops on the windward slope while the latter develops on the lee side (Figures 9 and 10). It is clear that convection can develop on both the windward slope and the lee-side of mountains, as indicated by a range of physical mechanisms including thermal [1] and dynamic forcing. The dynamic forcing, includes lee-side convergence [64], wake effects [20,21], flow into convergent valleys, orographic lifting, and upslope or downslope flows that are induced by heat or cold sources [65].

In order to investigate the possible mechanisms of LCDM initiation and development, perturbation of temperature and vertical circulation vectors (Figure 11) were analyzed using ECMWF_ERA5 hourly reanalysis data. Perturbation refers to the deviation of selected cases from 5-year (2014-2018) warm-season averages (April-September). The Dabie Mountains are a heat source leading to upward vertical motion (Figure 11a) and the formation of LCDM. Daniel et al. [66] also noted the contribution of terrain-induced ascent due to thermal forcing. It is demonstrated that most LCDM is possibly thermally forced. It is clear that both the 'South-Type' and 'North-Type' are controlled by southerly wind perturbations (Figure 11b,c); stronger southerly wind perturbation is below $900 \mathrm{hPa}$ for the 'South-Type' (Figure 11b), while stronger perturbations up to $700 \mathrm{hPa}$ are seen in the 'North-Type' (Figure 11c). For the windward slope convection ('South-Type'), strong southerly winds move halfway up the hill and are blocked by mountains, and then turn upwards again, leading to warm air being concentrated on the southern slopes. Lifting by upslope wind and heat sources in combination leads to LCDM development on the southern slopes, as previously indicated by earlier studies [67]. This upstream blocking process has been seen in numerous mountainous areas, including the Western Ghats Mountains of India [68], the Alps [69], and Northeastern Italy [70]. Additional possible mesoscale impacts, including storm outflows colliding with mountain upward winds [22-24], should be investigated further in the future. In terms of the 'North-Type', strong southerly winds can overflow mountains (Figure 11c), as illustrated by Figure 11c where ascending and descending features alternate (the blue rectangle in Figure 11c) between 850 and $500 \mathrm{hPa}$ above the mountains, possibly considered as a wave-like perturbation induced by flow and topographic interactions. Perturbations lead to ascent in the lee (the red ellipse in Figure 11c). A kind of mountain wave called a gravity wave formed on lee slopes, which was investigated in previous studies $[15,20,21]$. Whether the wave-like perturbations reported here are induced by gravity waves needs to be investigated using field experiments and numerical simulations in future research. Numerous theoretical and simulation studies have revealed the existence of a 
gravity wave, and although research has speculated on the importance of these waves in moist convection [20,71,72], few have presented convincing evidence for the occurrence of this phenomenon. This might be because of the high updraft altitude induced by waves, about $1.5-3 \mathrm{~km}$ above ground level (AGL) in the paper (Figure 11c). As the wave signal is weakened by reanalysis average data, this should be further investigated using field experiments and numerical simulations in future research.
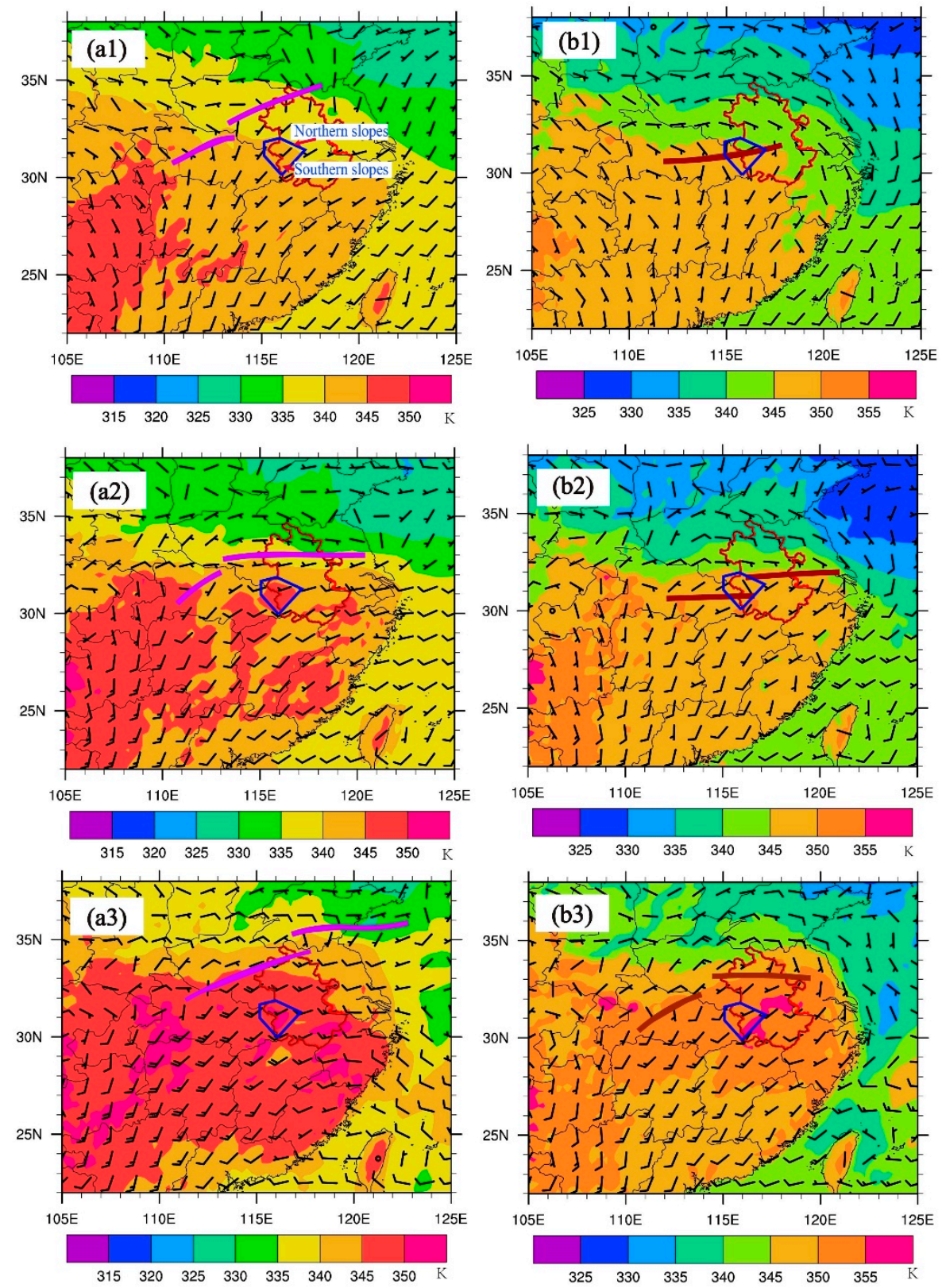

Figure 10. Horizontal wind at low levels ( 850 and $925 \mathrm{hPa}$, barbs, the full barb represent $4 \mathrm{~m} / \mathrm{s}$ ) and pseudo equivalent potential temperature (shaded, unit: K) of (a1,b1) LCDM, (a2,b2) 'South-Type' and $(\mathbf{a} 3, \mathbf{b 3})$ 'North-Type'. (a1-a3) represent $850 \mathrm{hPa}$. (b1-b3) represent $925 \mathrm{hPa}$. The purple and brown solid line represents shear line at 850 and $925 \mathrm{hPa}$, respectively. The blue polygon represents the Dabie Mountains. 


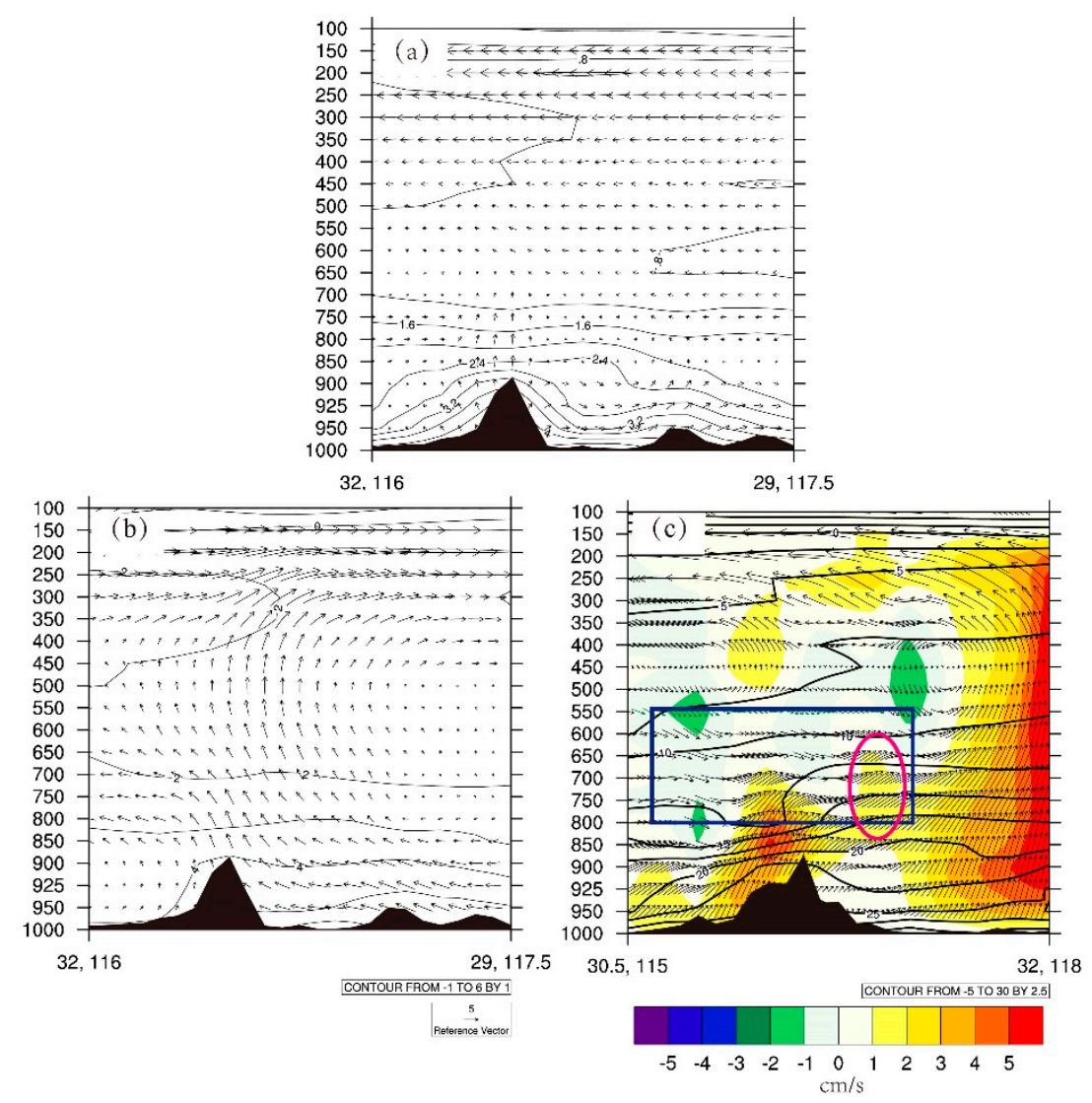

Figure 11. (a) LCDM and (b) 'South-Type' along the line 'HI' in Figure 9a: Vertical profiles of the perturbation of vertical circulation vectors (horizontal wind along cross section and 100 times the vertical velocity, vector: $\mathrm{m} / \mathrm{s}$ ), temperature (contour, unit: $\mathrm{K}$ ) and terrain height (black shaded, unit: $\mathrm{hPa}$ ) along the line illustrated in Figure 9. (c) 'North-Type' along the line 'JK' in Figure 9b: Vertical profiles of the perturbation of vertical circulation vectors (horizontal wind along cross section and 100 times the vertical velocity, vector: $\mathrm{m} / \mathrm{s}$ ), equivalent potential temperature (contour, unit: $\mathrm{K}$ ) and terrain height (black shaded, unit: $\mathrm{hPa}$ ) and vertical velocity (shaded, unit: $\mathrm{cm} / \mathrm{s}$ ) along the line illustrated in Figure 9. The perturbation is deviation from 5-year (2014-2018) warm seasons (April-September) average by using ECMWF_ERA5 reanalysis data.

\subsection{Tracks and Severe Convective Weather}

It is revealed that the 'South-Type' that initiated on windward slopes comprises two major paths. The dominant one is that convection initiates to the south of the Dabie Mountains (i.e., AR and BR areas in Figure 3a) and then moves northeastwards along the southern slopes in a southwest-northeast direction (the purple lines in Figure 12a1). The second path is that convection initiates in both AR and BR areas (Figure 3a), which then moves southeastwards into the Yangtze River valley (the green lines in Figure 12a1). Maximum intensities of hourly precipitation are observed on these two paths, especially the first one (Figure 12b1), while THWs occur mainly within eastern plain and southern valley areas (Figure 12c1). 

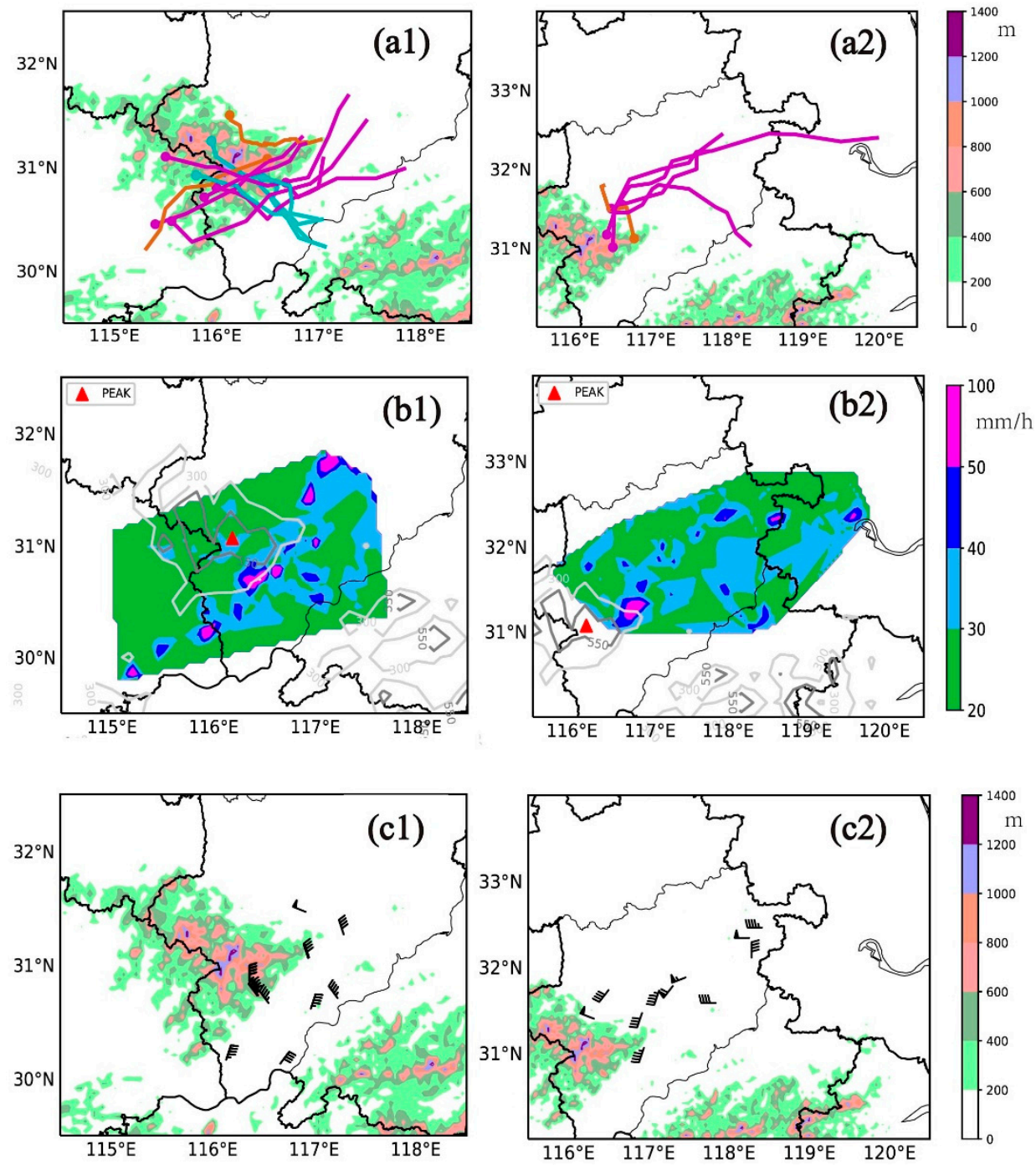

Figure 12. The tracks of (a1) 'South-Type' and (a2) 'North-type'; the spatial distribution of maximum hourly precipitation (shaded, unit: mm/h)of (b1) 'South-Type' and (b2) 'North-Type'; the spatial distribution of THWs (instantaneous wind speed $\geq 17 \mathrm{~m} / \mathrm{s}$ ) of (c1) 'South-Type' and (c2) 'North-Type'. The shaded in $(\mathbf{a} 1, \mathbf{a} 2, \mathbf{c} 1, \mathbf{c} 2)$ represent terrain height (unit: $\mathrm{m})$. The contour in (b1) and (b2) represent terrain height (unit: $\mathrm{m}$ ).

The 'North-Type' developed on lee sides (the CR area in Figure 3a) and then moved eastwards onto the plains (Figure 12a2). SDHR and THWs events occur frequently along this path, with maximum hourly precipitation intensity of about 50 and $70 \mathrm{~mm} / \mathrm{h}$ (Figure 12b2,c2). THWs mainly occur in plain areas while SDHR is observed at the junction between the mountains and plains.

\section{Conclusions and Discussion}

LCDMs that occurred during 2014-2018 in warm seasons (April-September) were investigated here using composite reflectivity data. A total of 195 cases were identified, which reveals an increasing annual trend. LCDM genesis is complex across the different areas of the Dabie Mountains. Local convections, especially severe ones, are mostly triggered on southern slopes (on windward slopes), while some (about $25 \%$ of the total) tend to initiate on lee slopes. At the same time, rare convections also initiate on hilltops. Monthly variations show a peak in July and August, while diurnal variations indicate the afternoon convections. The monthly and diurnal variations in LCDM may indicate thermally induced characteristics. The average lifetime is $3.7 \mathrm{~h}$ and most dissipate in the late afternoon 
(17:00-19:00 BST). LCMD on lee slopes initiate and dissipate one hour earlier than their counterparts on windward slopes.

It is revealed that just $8.7 \%$ of LCDMs move away from the Dabie Mountains (Out-Type) and the lifespans of these events ( $5.8 \mathrm{~h}$ on average) are longer than their NoOut-Type counterparts ( $3.5 \mathrm{~h}$ on average), as well as for MCSs [27] and squall lines [28] across East China. It is clear that Out-Type develop on both southern and northern slopes, defined as 'South-Type' and 'North-Type', respectively. The 'South-Type' accounts for $70 \%$ of the total, while the 'North-Type' accounts for the remaining $30 \%$. LCMDs mainly produce SDHR, observed to the south and east of the Dabie Mountains and corresponding to the distribution of strong echoes on windward slopes. Precipitation around the Dabie Mountains is heavier at the junction between mountains and plains. Just 3.5\% of LCDMs produce THWs, most of which $(86 \%)$ are generated by Out-Type events.

Data show that 'South-Type' and 'North-Type' events exhibit different characteristics. 'South-Type' events develop on windward slopes, while 'North-Type' events develop on lee slopes. It is clear that 'South-Type' events mostly produce SDHR, while 'North-Type' ones predominantly generate THWs. Most 'South-Type' events move along southern slopes, influencing northeastern plain areas. It is clear that 'North-Type' events mostly move onto northeastern plain areas. SDHR and THW events are mainly observed along these two paths.

It is clear that LCDM can both initiate and develop on windward and lee-side slopes. This indicates that several distinct physical mechanisms can lead to convection activity in mountainous areas. The Dabie Mountains area is a heat source in terms of LCDM, which leads to ascent, indicating thermally induced convections. It is clear that both the 'South-Type' and 'North-Type' are controlled by southerly wind perturbation. Strong southerly wind perturbation is located at the halfway up the hills for the 'South-Type', while this can overflow the mountains for the 'North-Type'. Lifting due to upslope winds and heating sources over windward slopes in the 'South-Type' leads to LCDM development on southern slopes. Wave-like perturbation ascent corresponds to convections development in the lee in the case of 'North-Type' events.

Both the 'South-Type' and 'North-Type' bring severe events to the adjcent areas and should be given more attention. Specilly, most 'North-Type' events bring THWs. However, their development mechanisms are not very clear. According to the synoptic analysis, they occur in the warm sector without synoptic force. Although a wave-like perturbation may possibly lead to 'North-Type' development, many issues with their mechanism should be studied further. For example, what if the forced mechanisms are at ground surface? What is the interaction between topography and boundary wind? Why do the 'North-Type' favorably generate THWs? All these issues need to be investigated using field experiments and numerical simulations.

Although the results of this study highlight major LCDM characteristics based on five years of radar reflectivity data, the case reported here is limited in terms of climatology characteristics. Further years of radar data need to be added to supplement the results presented in this analysis. Indeed, the observational station data relating to THWs and hails are also very limited, especially in the middle of the Dabie Mountains. Additional detailed observational data will be recorded in the future and convection-related weather characteristics within the Dabie Mountains will be explored with additional research.

Author Contributions: L.Z. designed the research and wrote the first draft of the paper. L.Z. and Z.Y. analyzed the data. J.S. revised the first draft and provided useful insights. L.Z., Z.Y. and X.Q. reviewed and modified the manuscript. All authors have read and agreed to the published version of the manuscript.

Funding: Supported by Natural Science Foundation of China (Grant 41705029 and 41975056), Key Research and Development Projects in Anhui Province (201904a07020099).

Conflicts of Interest: The authors declare no conflict of interest. 


\section{References}

1. Banta, R.M.; Schaaf, C.L.B. Thunderstorm genesis zones in the Colorado Rocky Mountains as determined by traceback of geosynchronous satellite images. Mon. Weather Rev. 1987, 115, 463-476. [CrossRef]

2. Aoshima, F.; Behrendt, A.; Bauer, H.S.; Wulfmeyer, V. Statistics of convection initiation by use of Meteosat rapid scan data during the Convective and Orographically-induced Precipitation Study (COPS). Meteorol. Ztschrif 2008, 17, 921-930. [CrossRef]

3. Bluestein, H.B.; Golden, J.H. A review of tornado observations. The Tornado: Its Structure, Dynamics, Prediction, and Hazards. Geophys. Monogr. 1993, 79, 319-352.

4. Wakimoto, R.M. Forecasting dry microburst activity over the high plains. Mon. Weather Rev. 1985, 113, 1131-1143. [CrossRef]

5. Doswell, C.A. Synoptic-scale environments associated with high plains severe thunderstorms. Bull. Am. Meteor. Soc. 1980, 61, 1388-1400. [CrossRef]

6. Wojtiw, L. Climate Summaries of Hailfall in Central Alberta (1957-73); Alberta Research Council: Edmonton, AB, Canada, 1975; 102p.

7. Smith, S.B.; Yau, M.K. The mesoscale effect of topography on the genesis of Alberta hailstorms. Beitr. Phys. Atmos. 1987, 60, 371-392.

8. Houze, R.A.; Schmid, W.; Fovell, R.G.; Schiesser, H.H. Hailstorms in Switzerland: Left movers, right movers, and false hooks. Mon. Weather Rev. 1993, 121, 3345-3370. [CrossRef]

9. Zheng, L.L.; Sun, J.H.; Wei, J. Thunder events in China: 1980-2008. Atmos. Ocean. Sci. Lett. 2010, 3, 181-188.

10. Yu, R.; Zhang, X.; Li, G.; Gao, Q. Analysis of frequency variation of thunderstorm, hail and gale wind in Eastern China from 1971 to 2000. Meteorol. Mon. 2012, 38, 1207-1216. (In Chinese)

11. Liu, H.; Hi, W.; Huang, X. Statistical analysis of merger characteristic of convective cloud on July in Dabie Mountains. J. Atmos. Environ. Opt. 2010, 5, 33-39. (In Chinese)

12. Zhang, J.; Yuan, S.; Yao, Y. Analysis on consistency of thunderstorm data from lightening detection network and manual observation in the Yangtze and Huaihe River region. Torrential Rain Disasters 2015, 34, $286-292$. (In Chinese)

13. Zhou, K.; Pan, Y.; Wang, D.; Chen, B. Numerical simulations of the orographic effects of the Dabie Mountains on the mesoscale convective system of a spring cold front. J. Nanjing Univ. (Nat. Sci.) 2007, 43, 535-543. (In Chinese)

14. Zhao, Y.; Zhao, G.; Miao, C.; Bo, Y. Analysis of the terrain sensitivity torrential rain in Jianghuai region 2007-07-07. Sci. Technol. Innov. 2015, 3, 28-30. (In Chinese)

15. Zhu, M.; Yu, Z.H.; Lu, H.C. The effect of meso-scale lee wave and its application. Acta Metorologocal Sin. 1999, 57, 705-714. (In Chinese)

16. Zhao, Y.; Xu, X.; Cui, C. Case study of the impact of mesoscale topography on Meiyu frontal rainstorm. Plateau Meteorol. 2012, 31, 1268-1281. (In Chinese)

17. Dong, M.; Chen, L.; Cheng, Z.; Li, Y. Numerical study of topography effect on rainfall reinforcement associated with Tropical Cyclone 'Talim'. Plateau Meteorol. 2011, 30, 700-710. (In Chinese)

18. Kovacs, M.; Kirshbaum, D.J. Topographic impacts on the spatial distribution of deep convection over southern Quebec. J. Appl. Meteor. Climatol. 2016, 55, 743-762. [CrossRef]

19. Lanicci, J.M.; Warner, T.T. A synoptic climatology of the elevated mixed-layer inversion over the Southern Great Plains in spring. Part I: Structure, dynamics, and seasonal evolution. Weather Forecast. 1991, 6, $198-213$. [CrossRef]

20. Tripoli, G.J.; Cotton, W.R. Numerical study of an observed orogenic mesoscale convective system. Part I: Simulated genesis and comparison with observations. Mon. Weather Rev. 1989, 117, 273-304. [CrossRef]

21. Tripoli, G.J.; Cotton, W.R. Numerical study of an observed orogenic mesoscale convective system. Part II: Analysis of governing dynamics. Mon. Weather Rev. 1989, 117, 304-328.

22. Szoke, E.J.; Mueller, C.K.; Wilson, J.W.; Zipser, E.J. Development of convection and severe weather along outflow boundaries in northeast Colorado: Diagnosing the above-surface environment with a mobile sounding system. Preprints, 14th Conference on Severe Local Storms, Indianapolis, IN. Am. Meteor. Soc. 1985, 66, 386-389.

23. Wilson, J.W.; Schreiber, W.E. Initiation of convective storms at radar-observed boundary-layer convergence lines. Mon. Weather Rev. 1986, 114, 2516-2536. [CrossRef] 
24. Jou, B.J.D. Mountain-originated mesoscale precipitation system in northern Taiwan: A case study 21 June 1991. Terr. Atmos. Oceanic. Sci. 1994, 5, 169-197. [CrossRef]

25. Kuo, J.T.; Orville, H.D. A Radar climatology of summertime convective clouds in the Black Hills. J. Appl. Meteorol. 1973, 12, 359-367. [CrossRef]

26. Lin, P.F.; Chang, P.L.; Jou, J.D.; Wilson, J.W.; Roberts, R.D. Warm season afternoon thunderstorm characteristics under weak synoptic-scale forcing over Taiwan island. Weather Forecast. 2011, 26, 44-60. [CrossRef]

27. Zheng, L.; Sun, J.; Zhang, X.; Liu, C. Organizational modes of mesoscale convective systems over central East China. Weather Forecast. 2013, 28, 1081-1098. [CrossRef]

28. Meng, Z.; Zhang, F. On the squall lines preceding landfalling tropical cyclones in China. Mon. Weather Rev. 2012, 140, 445-470. [CrossRef]

29. Meng, Z.; Yan, D.; Zhang, Y. General features of squall lines in East China. Mon. Weather Rev. 2013, 141, 1629-1647. [CrossRef]

30. Han, F.; Wo, W. Design and implementation of SWAN2.0 platform. J. Appl. Meteorol. Sci. 2018, 1, 25-34. (In Chinese)

31. Wu, T.; Wan, Y.; Wo, W.; Leng. L. Design and application of Radar reflectivity quality control algorithm in SWAN. Meteorol. Sci. Technol. 2013, 41, 809-817. (In Chinese)

32. Parker, M.D.; Knievel, J.C. Do meteorologists suppress thunderstorms?: Radar-derived statistics and the behavior of moist convection. Bull. Am. Meteorol. Soc. 2005, 86, 341-358. [CrossRef]

33. Chen, M.; Wang, Y.; Gao, F.; Xiao, X. Diurnal variations in convective storm activity over contiguous North China during the warm season based on radar mosaic climatology. J. Geophys. Res. 2012, 117, D20115. [CrossRef]

34. Lin, C.Y.; Chen, W.C.; Chang, P.L. Impact of the urban heat island effect on precipitation over a complex geographic environment in northern Taiwan. J. Appl. Meteorol. Climatol. 2011, 50, 339-353. [CrossRef]

35. Chechik, G.; Shalit, U.; Sharma, Y. An Online Algorithm for Large Scale Image Similarity Learning. In Proceedings of the Advances in Neural Information Processing Systems 22: 23rd Annual Conference on Neural Information Processing Systems 2009, Vancouver, BC, Canada, 7-10 December 2009; Curran Associates Inc.: New York, NY, USA, 2009.

36. Hereford, J.M.; Rhodes, W.T. Nonlinear Optical Image Filtering By Time-Sequential Threshold Decomposition. Opt. Eng. 1988, 27, 274. [CrossRef]

37. Liu, H.; Hou, X. The Precise Location Algorithm of License Plate Based on Gray Image. In Proceedings of the Computer Science \& Service System (CSSS), 2012 International Conference on. IEEE Computer Society, Nanjing, China, 11-13 August 2012.

38. Juhola, M.; Katajainen, J.; Raita, T. Comparison of algorithms for standard median filtering. IEEE Trans. Signal Process. 2002, 39, 204-208. [CrossRef]

39. IPCC. Special Report on Global Warming of $1.5^{\circ} \mathrm{C}$; Cambridge University Press: Cambridge, UK, 2018.

40. Qi, Q.; Cai, R.; Guo, H. The Climatic Variations of Temperature Extremes in the Eastern of China. Sci. Geogr. Sin. 2019, 39, 1340-1350. [CrossRef]

41. Johnson, R.H.; Bresch, J.F. Diagnosed characteristics of precipitation systems over Taiwan during the May-June 1987 TAMEX. Mon. Weather Rev. 1991, 119, 2540-2557. [CrossRef]

42. Lin, S.M.; Kuo, H.C. A study of summertime afternoon convection in southern Taiwan during 1994 (in Chinese with English abstract). Atmos. Sci. 1996, 24, 249-280.

43. Chen, G.T.J.; Chou, H.C.; Chang, T.C. Frontal and non-frontal convection over northern Taiwan in mei-yu season (in Chinese with English abstract). Atmos. Sci. 2001, 29, 37-52.

44. Henz, J.F. Characteristics of severe convective storms in Colorado High Plains. Preprints, Eighth Conf. on Severe Local Storms, Denver, Colorado. Amer. Meteor. Soc. 1973, 113, 96-103.

45. Karr, T.W.; Wooten, R.L. Summer radar echo distribution around Limon, CO. Mon. Weather Rev. 1976, 104, 728-734. [CrossRef]

46. Klitch, M.A.; Weaver, J.F.; Kelly, F.P.; Vonder Haar, T.H. Convective cloud climatologies constructed from satellite imagery. Mon. Weather Rev. 1985, 113, 326-337. [CrossRef]

47. Yang, R.; Zhang, Y.; Sun, J.; Fu, S.; Li, J. The characteristics and classification of eastward-propagating mesoscale convective systems generated over the second-step terrain in the Yangtze River Valley. Atmos. Sci. Lett. 2018, 20, e874. [CrossRef] 
48. Sun, J. The effect of vertical distribution of the lower level flow on precipitation location. Plateau Meteorol. 2005, 24, 62-69. (In Chinese)

49. Ni, T.; Huang, Y.; Ling, X.; Huang, G.; Li, J. Characteristics of orographic precipitation in Dabie Mountain. Meteorol. Sci. Technol. 2018, 46, 556-562. (In Chinese)

50. Jirak, I.L.; Cotton, W.R.; Mcanelly, R.L. Satellite and Radar Survey of Mesoscale Convective System Development. Mon. Weather Rev. 2003, 131, 2428. [CrossRef]

51. Tao, S.Y. Heavy Rainfalls in China; Science Press: Beijing, China, 1980; 225p. (In Chinese)

52. Luo, Y.L.; Wang, H.; Zhang, R.H.; Qian, W.M.; Luo, Z.Z. Comparison of rainfall characteristics and convective properties of monsoon precipitation systems over south China and the Yangtze and Huai River basin. J. Clim. 2013, 26, 110-132. [CrossRef]

53. Wang, Q.W.; Xue, M.; Tan, Z.M. Convective initiation by topographically induced convergence forcing over the Dabie Mountains on 24 June 2010. Adv. Atmos. Sci. 2016, 33, 1120-1136. [CrossRef]

54. Weckwerth, T.M.; Wilson, J.W.; Hagen, M.; Emerson, T.J.; Pinto, J.O.; Rife, D.L.; Grebe, L. Radar climatology of the COPS region. Q. J. R. Meteorol. Soc. 2011, 137, 31-41. [CrossRef]

55. Chen, M.; Wang, Y.; Gao, F.; Xiao, X. Diurnal evolution and distribution of warm-season convective storms in different prevailing wind regimes over contiguous North China. J. Geophys. Res. Atmos. 2014, 119, 2742-2763. [CrossRef]

56. Carbone, R.E.; Tuttle, J.D. Rainfall occurrence in the U.S. warm season: The Diurnal Cycle. J. Clim. 2008, 21, 4132-4146. [CrossRef]

57. Tong, J.; Wei, L.X.; Ye, J.Y.; Zhou, K.; Yuan, S. Spatial-temporal distribution characteristics of short-time strong precipitation in the flood season under different terrains over Anhui province. J. Meteorol. Environ. 2017, 33, 42-48.

58. Yang, X.L.; Sun, J.H. Organizational modes of severe wind-producing convective systems over North China. Adv. Atmos. Sci. 2018, 35, 540-549. [CrossRef]

59. Doswell, C.A.; Brooks, H.E.; Kay, M.P. Climatological estimates of daily local nontornadic severe thunderstorm probability for the United States. Weather Forecast. 2005, 20, 577-595. [CrossRef]

60. Egger, J. Valley winds and the diurnal circulation over plateaus. Mon. Weather Rev. 1987, 115, $2177-2186$. [CrossRef]

61. Yang, K.; Koike, T.; Fujii, H.; Tamura, T.; Xu, X.; Bian, L.; Zhou, M. The daytime evolution of the atmospheric boundary layer and convection over the Tibetan Plateau: Observations and simulations. J. Meteor. Soc. Jpn. 2004, 82, 1777-1792. [CrossRef]

62. Bhatt, B.C.; Nakamura, K. A climatological-dynamical analysis associated with precipitation around the southern part of the Himalayas. J. Geophys. Res. 2006, 111, D02115. [CrossRef]

63. Liu, X.; Bai, A.; Liu, C. Diurnal variations of summertime precipitation over the Tibetan Plateau in relation to orographically-induced regional circulations. Environ. Res. Lett. 2009, 4, 045203. [CrossRef]

64. Szoke, E.J.; Weisman, M.L.; Brown, J.M.; Caracena, F.; Schlatter, T.W. A subsynoptic analysis of the Denver tornadoes of 3 June 1981. Mon. Weather Rev. 1984, 112, 790-808. [CrossRef]

65. Tucker, D.F.; Crook, N.A. Flow over heated terrain. Part II: Generation of convective precipitation. Mon. Weather Rev. 2005, 133, 2565-2582. [CrossRef]

66. Daniel, K.; Bianca, A.; Norbert, K.; Christian, B.; Stefano, S. Moist Orographic convection: Physical mechanisms and links to surface-exchange processes. Atmosphere 2018, 9, 80.

67. Johnson, R.H.; Mapes, B.E. Mesoscale processes and severe convective weather. In Severe Convective Storms; American Meteorological Society: Boston, MA, USA, 2001; pp. 71-122.

68. Grossman, R.L.; Durran, D.R. Interaction of low-level flow with the western Ghat Mountains and offshore convection in the summer monsoon. Mon. Weather Rev. 1984, 112, 652-672. [CrossRef]

69. Houze, R.A., Jr.; James, C.N.; Medina, S. Radar observations of precipitation and airflow on the Mediterranean side of the Alps: Autumn 1998 and 1999. Q. J. R. Meteorol. Soc. 2001, 127, 2537-2558. [CrossRef]

70. Davolio, S.; Volonté, A.; Manzato, A.; Pucillo, A.; Sicogna, A.; Ferrario, M.E. Mechanisms producing different precipitation patterns over north-eastern Italy: Insights from HyMeX-SOP1 and previous events. Q. J. R. Meteorol. Soc. 2016, 142, 188-205. [CrossRef]

71. Houze, R.A. Orographic effects on precipitating clouds. Rev. Geophys. 2012, 50, RG1001. [CrossRef] 
72. Tian, W.S.; Parker, D.J. A modeling study and scaling analysis of orographic effects on boundary layer shallow convection. J. Atmos. Sci. 2003, 60, 1981-1991. [CrossRef]

Publisher's Note: MDPI stays neutral with regard to jurisdictional claims in published maps and institutional affiliations.

(C) 2020 by the authors. Licensee MDPI, Basel, Switzerland. This article is an open access article distributed under the terms and conditions of the Creative Commons Attribution (CC BY) license (http://creativecommons.org/licenses/by/4.0/). 